\title{
A spontaneous 99-kb chromosomal deletion results in multi-antibiotic susceptibility and an attenuation of contact haemolysis in Shigella flexneri $2 a$
}

\author{
K. RAJAKUMAR, C. SASAKAWA* and B. ADLER \\ Department of Microbiology, Monash University, Wellington Road, Clayton, Victoria 3168, Australia and \\ * Department of Bacteriology, Institute of Medical Science, University of Tokyo, 4-6-1, Shirokanedai, Minato-ku, \\ Tokyo 108, Japan
}

\begin{abstract}
A Tn5-generated mutant (strain S2430) of Shigella flexneri 2a (strain YSH6000) exhibited attenuated virulence and, in addition to the Tn5 insertion in the SalI K fragment of its virulence plasmid, had a 99-kb deletion within its chromosome. Unlike its wild-type parent, strain $\mathbf{S 2 4 3 0}$ was susceptible to ampicillin, streptomycin, tetracycline and chloramphenicol. An independent multi-antibiotic susceptible variant of strain YSH6000 had a similar deletion. Southern blot analysis of pulsed field electrophoresis gels enabled the sizing of this deletion and its mapping to a region of the chromosome on Not I fragment $D$ bounded by the $S$. flexneri homologues of ompA and pyrC. Hybridisation experiments with a probe specific to the multi-antibiotic resistance region indicated that this large deletion was responsible for antibiotic susceptibility. Both strain S2430 and a derivative of the antibiotic-susceptible variant, with a Tn5 insertion in its $\mathrm{Sal} \mathbf{I} \mathrm{K}$ fragment, exhibited an equal reduction in contact haemolysis compared with the Tn5-bearing derivative of strain YSH6000. However, strain S2430 alone clearly displayed delayed plaque forming ability in LLC-MK2 monolayers, suggesting that the two examples of this deletion may not be identical.
\end{abstract}

\section{Introduction}

Shigella spp., predominantly human pathogens, are the causative agents of bacillary dysentery. Disease follows ingestion of virulent organisms which invade the colonic epithelial cells, multiply intracellularly and spread to adjacent cells. The resulting inflammation and ulceration of the mucosa account for the symptoms of pyrexia, abdominal colic and bloody diarrhoea [1].

Many proteins play a role in this multi-step process of pathogenesis. The majority are encoded by a large 100-140-MDa plasmid present in all virulent strains of Shigella spp. and enteroinvasive Escherichia coli [2]. The antigens IpaBCD are essential for primary invasion $[3,4]$ which occurs via a process of bacteriadirected phagocytosis [5]. The IcsB [6] and VacJ [7] proteins are critical for intercellular spread and the many $m x i$ and spa gene products are required for normal surface expression and secretion of Ipa proteins [8-10]. VirG, a 116-kDa surface-exposed protein, facilitates intracellular and intercellular move-

Received 5 May 1995; accepted 25 Nov. 1995. Corresponding author: Dr K. Rajakumar. ment via the deposition of a trail of F-actin [11]. VirK regulates the post-transcriptional expression of VirG [12]; VirB [13] and VirF [14] are transcriptional activators involved in switching on the virulence phenotype.

Besides these plasmid-borne determinants, several chromosomal loci have been identified. The virR (hns) gene is responsible for temperature-dependent expression [15] and the $o m p B$ locus (envZ and ompR) governs osmoregulation of the many virulence genes [16]. Other critical determinants of virulence include the lipopolysaccharide biosynthetic genes [17], the iron siderophore aerobactin genes [18], the superoxide dismutase gene [19] and $v a c B$ which is involved in the post-transcriptional regulation of expression of IpaBCD and VirG [20].

Apart from the many virulence-associated determinants, another aspect of Shigella spp. of major clinical significance is the high prevalence of antibiotic multiresistant strains. Most of these strains harbour easily mobilisable resistance plasmids [21,22], but strains exhibiting non-transferable, possibly chromosomally located resistance genes have been identified [23]. However, no molecular studies have been performed to elucidate the basis of chromosomal resistance. 
This paper describes the further characterisation of a Tn5-generated mutant of $S$. flexneri $2 \mathrm{a}$ strain YSH6000. The mutant, S2430, had been shown previously to exhibit reduced contact haemolysis $(\mathrm{CH})$, delayed plaque forming ability in LLC-MK2 cell monolayers and a delayed ability to provoke keratoconjuctivitis in mice [24]. These workers had attributed this attenuation of virulence to a Tn5mediated disruption of a presumptive chromosomal virulence-associated locus, vacD. The present study examined the Tn5 insertion in strain S2430, the reduction in contact haemolytic activity ( $\mathrm{CHA}$ ) in relation to a spontaneous, 99-kb deletion from the chromosome and loss of resistance to the antibiotics chloramphenicol, streptomycin, tetracycline and ampicillin, to elucidate the origins of chromosomally encoded antibiotic multi-resistance in Shigella spp.

\section{Materials and methods}

\section{Bacterial strains, media and growth conditions}

The wild-type strain S. flexneri 2a YSH6000 [25], the antibiotic-susceptible derivative YSH6000T [12] and the virulence-plasmid-free derivative YSH6200 [14] have been described previously. Strain S2430 was constructed by Okada et al. [24]. The Tn5-bearing strains $\mathrm{K} 6000$ and K6000T were constructed by P1 transduction [18], with S2430 passaged lysate, of strains YSH6000 and YSH6000T, respectively. E. coli K-12 strain DH5 $\alpha$ was used for cloning. Strains were grown routinely at $37^{\circ} \mathrm{C}$ in $\mathrm{LB}$ media with the addition of kanamycin $50 \mathrm{mg} / \mathrm{L}$ when necessary. Antibiotic susceptibility was assayed by streaking individual clones on to LB agar supplemented with chloramphenicol $40 \mathrm{mg} / \mathrm{L}$, tetracycline $25 \mathrm{mg} / \mathrm{L}$, streptomycin $25 \mathrm{mg} / \mathrm{L}$ or ampicillin $100 \mathrm{mg} / \mathrm{L}$.

\section{Molecular biological techniques}

Genomic DNA was isolated by the small scale preparation method of Ausubel et al. [26]. Plasmid DNA was isolated by a modification of the alkaline lysis method [27]. The $230-\mathrm{kb}$ virulence plasmid was purified as described by Sasakawa et al. [25]. Standard cloning procedures with the plasmid vectors $\mathrm{pUC18} / 19$ or their trimethoprim-resistant derivatives pUC18/19Tp [28] were employed. The 3.3-kb native plasmid of strain YSH6000 [25] and the 6.5-kb mini-replicon derived from pMYSH6000 [29] were used as low copy number vectors. Transformation of $E$. coli was achieved following electroporation with a BioRad Gene Pulser. Nucleotide sequencing was performed by the dideoxy chain termination method [30].

Preparation of high mol.-wt (HMW) genomic DNA and pulsed field gel electrophoresis (PFGE)

HMW DNA was prepared as described by Smith and Cantor [31] with the exclusion of the detergent Brij-58 from the lysis solution. Low melting temperature (LMT) agarose plugs $(100 \mu \mathrm{l})$ containing $c .2 \mu \mathrm{g}$ of DNA were pre-equilibrated with digestion buffer before incubation for $16 \mathrm{~h}$ at $37^{\circ} \mathrm{C}$ with $10 \mathrm{U}$ of $N o t \mathrm{I}$ in a $250-\mu 1$ reaction mixture $(50 \mathrm{mM}$ Tris- $\mathrm{HCl}, \mathrm{pH} 7.5$; $10 \mathrm{mM} \mathrm{MgCl}_{2} ; 100 \mathrm{mM} \mathrm{NaCl} ; 1 \mathrm{mM}$ dithioerythritol, DTE; bovine serum albumin, BSA $100 \mathrm{mg} / \mathrm{L}$. Not $\mathrm{I} / S f i \mathrm{I}$ double digests were performed as a two-stage procedure with a 4 -h $50^{\circ} \mathrm{C}$ digestion with $10 \mathrm{U}$ of $S f i \mathrm{I}$ in reaction buffer $(10 \mathrm{mM}$ Tris- $\mathrm{HCl}, \mathrm{pH} 7.5 ; 10 \mathrm{mM}$ $\mathrm{MgCl}_{2} ; 50 \mathrm{mM} \mathrm{NaCl} ; 1 \mathrm{mM} \mathrm{DTE} ;$ BSA $100 \mathrm{mg} / \mathrm{L}$ ) followed by incubation for $16 \mathrm{~h}$ at $37^{\circ} \mathrm{C}$ with $10 \mathrm{U}$ of Not $\mathrm{I}$ as described earlier. After digestion, the agarose plugs were incubated in ES $(0.5 \mathrm{M}$ EDTA, $\mathrm{pH} 9.5$; lauroyl sarcosine $1 \%$ ) at $50^{\circ} \mathrm{C}$ for $2 \mathrm{~h}$ and equilibrated in TE (10 mM Tris, $\mathrm{pH} 8.0 ; 1 \mathrm{mM}$ EDTA) at room temperature before PFGE in a CHEF BioRad system in agarose $1 \%$ gels and a running buffer consisting of $0.5 \times$ TBE $(44.5 \mathrm{mM}$ Tris; $44.5 \mathrm{mM}$ boric acid; $1 \mathrm{mM}$ EDTA). Gels were electrophoresed at $180 \mathrm{~V}$ for $24 \mathrm{~h}$ with pulse times of $20-25 \mathrm{~s}$, at $14^{\circ} \mathrm{C}$.

\section{Southern hybridisation}

After electrophoresis, DNA was transferred on to positively-charged nylon membranes (Boehringer Mannheim) by a vacuum blotting apparatus (TE80 TransVac, Hoefer) and a protocol involving three consecutive 10-20-min steps in depurination $(0.25 \mathrm{M}$ $\mathrm{HCl}$ ), denaturation (1.5 M NaCl; $0.5 \mathrm{M} \mathrm{NaOH})$ and neutralisation ( $1 \mathrm{M}$ Tris, $\mathrm{pH} 7.0 ; 1.5 \mathrm{M} \mathrm{NaCl})$ solutions. This was followed by $1-2-\mathrm{h}$ transfer with $20 \times$ SSC $(3 \mathrm{M} \mathrm{NaCl} ; 0.3 \mathrm{M}$ sodium citrate). Membranes were then baked at $80^{\circ} \mathrm{C}$ for $2 \mathrm{~h}$ and hybridisation was performed over $16 \mathrm{~h}$ under conditions of high stringency. Probes used in this study were labelled with digoxygenin with protocols described by the manufacturer (Boehringer Mannheim). Besides those previously described, they consisted of the 1.5-kb Bgl II / Hpa I fragment of Tn5 (IS50), the $1.0-\mathrm{kb} \quad B g l \mathrm{II} / S m a \mathrm{I}$ fragment of Tn5 (kanamycin resistance gene), the 2.9-kb Dra I/Hpa I fragment of pSBA61 (this study, DNA flanking transposon in strain S2430), the 1.2-kb EcoRI/HindIII fragment of pTU500 (ompA) [32], the 1.6-kb Pst I fragment of pLF4 (ompF) [33] and the 1.6$\mathrm{kb}$ EcoRI fragment of pBHM107 (pyrC) [34]. The Not I fragment D of YSH6000 was purified by Agarase treatment from LMT gel after PFGE. The purified fragment was digested with Sau3AI before a standard random primed labelling reaction. Chemiluminescent detection with Lumigen PPD (Boehringer Mannheim) was used routinely. When required, the membranes were stripped by the protocol provided by Boehringer Mannheim.

\section{Virulence phenotype assays}

The (Congo red binding) Pcr phenotype was assessed by streaking different strains on to two halves of LB 
agar plates supplemented with Congo red $0.01 \%$. The plates were streaked in duplicate and incubated overnight at both $37^{\circ} \mathrm{C}$ and $42^{\circ} \mathrm{C}$, after which the Pcr phenotype was scored by direct comparison between the two strains on the same plate.

The $\mathrm{CH}$ assay was based on the method of Sansonetti et al. [35]. Bacteria were grown for $3 \mathrm{~h}$ at $37^{\circ} \mathrm{C}$ in trypticase soy broth with or without kanamycin $50 \mathrm{mg} /$ $\mathrm{L}$. Cultures were centrifuged at $4000 \mathrm{~g}$, washed with PBS $\quad\left(137 \mathrm{mM} \quad \mathrm{NaCl} ; 6.5 \mathrm{mM} \quad \mathrm{K}_{2} \mathrm{HPO}_{4} ; 2.5 \mathrm{mM}\right.$ $\mathrm{KH}_{2} \mathrm{PO}_{4} ; \mathrm{pH} 7.2$ ) and concentrated c. 40-fold. Varying dilutions of this bacterial concentrate in PBS were used in the $\mathrm{CH}$ assay and appropriate dilutions were also plated to obtain accurate bacterial counts. The bacterial dilutions were each pre-mixed with an equal volume of freshly washed sheep erythrocytes suspended in PBS at a concentration of $c .1 \times 10^{10} / \mathrm{ml}$. One hundred $\mu \mathrm{l}$ of the bacteria/erythrocyte mixtures were dispensed into each well of a 96-well flat-bottom microtitration plate. The plates were centrifuged at $1500 \mathrm{~g}$ for $15 \mathrm{~min}$ at room temperature before incubation for $1 \mathrm{~h}$ at $37^{\circ} \mathrm{C}$. The bacteria/erythrocyte pellets were then resuspended with $150 \mu \mathrm{l}$ of fresh PBS/well. The microtitration plates were centrifuged once again before removal of $100 \mu$ l of supernate from each well. Haemolysis was assayed by measuring the absorbance of the supernate at $570 \mathrm{~nm}$.

The focus plaque assay (Fpa) was performed as described by Sasakawa et al. [36]. Confluent LLCMK2 monolayers established in 96-well tissue culture trays were infected with the various bacterial strains at a multiplicity of infection of $c .5 \times 10^{3}$. The monolayers were observed with low power light microscopy over a 72-h period. Photographs were taken at 24 and $40 \mathrm{~h}$ post-infection to document progression of plaques.

\section{Results}

\section{Mapping of the Tn5 insertion in $S 2430$}

A 7.6-kb EcoRV fragment containing the entire Tn5 and $1.9 \mathrm{~kb}$ of flanking shigella DNA was cloned into pUC1 8 by selecting for kanamycin resistance, generating the plasmid pSBA61. The flanking regions were partially sequenced and appropriate primers were synthesised and used in a PCR reaction to generate the 1.9-kb fragment from the wild-type strain YSH6000 DNA. This PCR fragment was cloned and its restriction digest profile was identical to that of a $1.9-\mathrm{kb}$ segment of DNA bounded by EcoRV sites on the SalI K fragment of the virulence plasmid pMYSH6000 [12]. Furthermore, the SalI profile of the virulence plasmid of strain S2430 was identical to that of strain YSH6000 except that it lacked the wild-type 7.8-kb SalI fragment and, instead, had two additional fragments of $7.3 \mathrm{~kb}$ and $6.2 \mathrm{~kb}$, consistent with the insertion of a $5.7-\mathrm{kb}$
Tn5 element, bearing a unique $S a l$ I site, into the $S a l$ I $\mathrm{K}$ fragment of strain S2430. Southern blots with both IS50 and kanamycin resistance gene probes confirmed that this was the only copy of Tn 5 in strain S2430.

\section{Cloning of three antibiotic resistance determinants}

Conjugation studies had shown that strain S2430, unlike the parent strain YSH6000, had become susceptible to tetracycline $25 \mathrm{mg} / \mathrm{L}$, ampicillin $100 \mathrm{mg} / \mathrm{L}$, chloramphenicol $40 \mathrm{mg} / \mathrm{L}$ and streptomycin $25 \mathrm{mg} / \mathrm{L}$. Three of the wild-type antibiotic resistance determinants were cloned to characterise this deletion. DNA from strain YSH6000 was digested with EcoRI, HindIII or Pst I, and ligated to appropriately prepared pUC18 vectors. Transformants were selected on the basis of chloramphenicol, streptomycin or tetracycline resistance. An 8.9-kb HindIII fragment resulting in chloramphenicol resistance, and a $2.2-\mathrm{kb}$ HindIII fragment conferring streptomycin resistance were isolated. When the $8.9-\mathrm{kb}$ fragment was cloned into lowcopy number plasmids, tetracycline resistance also was expressed.

\section{Southern blot analysis with probes linked to resistance determinants}

The 8.9-kb HindIII fragment encoding both chloramphenicol and tetracycline resistance was labelled and used in a Southern blot experiment to probe the nature of the genetic alteration in strain S2430. This yielded a multi-band background profile consistent with the presence of repeat elements on the chromosome of both YSH6000 and its mutant S2430. However, there was no specific $8.9-\mathrm{kb}$ HindIII hybridising band in strain S2430, indicating a deletion linked to the resistance determinants in this strain. To clarify these results, a $0.2-\mathrm{kb}$ HindIII/HindII fragment derived from the 8.9-kb HindIII fragment was used in a Southern blot to probe genomic DNA from strains YSH6000, S2430 and YSH6000T, a spontaneous variant of strain YSH6000 known to be susceptible to all four antibiotics [12]. The $0.2-\mathrm{kb}$ probe hybridised with the predicted restriction fragments in strain YSH6000 while the corresponding fragments in strains S2430 and YSH6000T were absent (Fig. 1), thus confirming that a deletion linked to the resistance determinants had occurred in both strains S2430 and YSH6000T. The additional bands seen in Fig. 1A correspond to the small native plasmids in these strains and appear to be the result of non-specific hybridisation. Southern blot hybridisation with a 1.7-kb HindIII/HindII fragment derived from the opposite end of the $8.9-\mathrm{kb}$ HindIII fragment (Fig. 1B) showed that this region of DNA also had been deleted in strains S2430 and YSH6000T, leading to the conclusion that a minimum of $8.9 \mathrm{~kb}$ of DNA had been deleted in these strains (results not shown). 
A

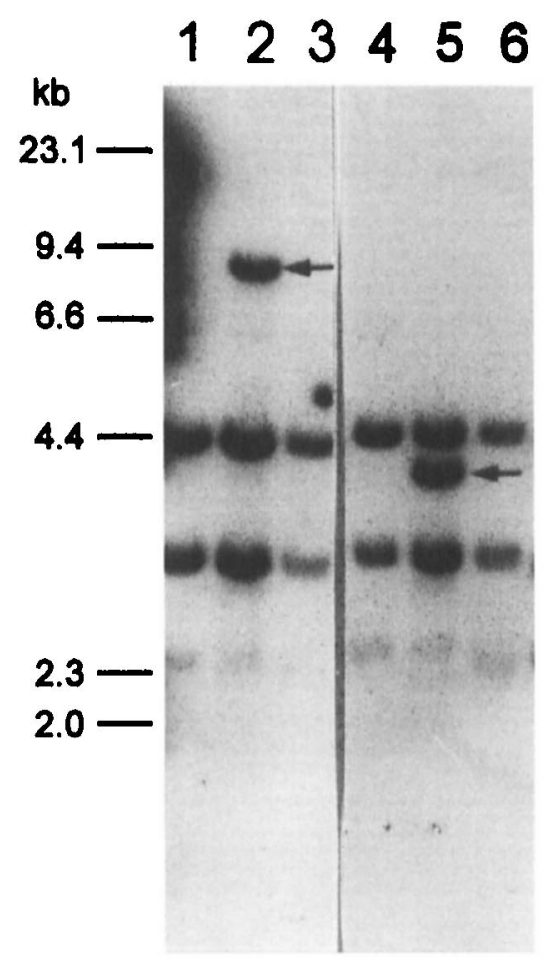

B

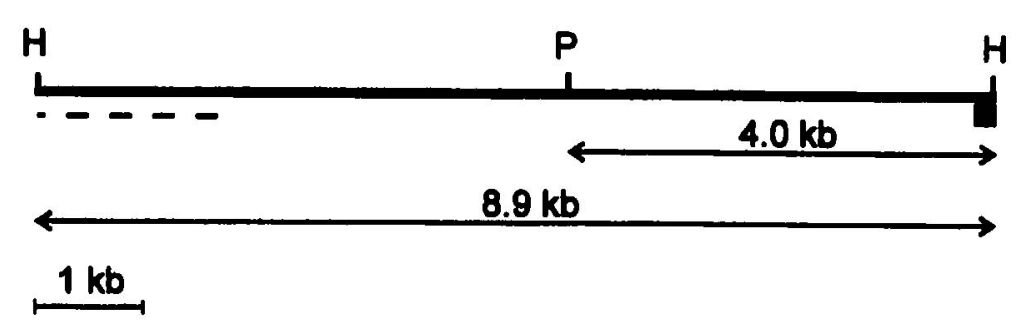

Fig. 1. (A) Southern hybridisation analysis with a 0.2-kb HindIII/HindII probe derived from the 8.9-kb HindIII fragment of strain YSH6000 encoding both chloramphenicol and tetracycline resistance. Lane 1, strain YSH6000T DNA digested with HindIII; 2, strain YSH6000 DNA digested with HindIII; 3, strain S2430 DNA digested with HindIII; 4, strain YSH6000T DNA digested with HindIII/PstI; 5, strain YSH6000 DNA digested with HindIII/Pst I; 6, strain S2430 DNA digested with HindIII/Pst I. Arrows indicate the 8.9-kb and 4.0-kb hybridising bands in strain YSH6000. The sizes in $\mathrm{kb}$ of $\lambda$ HindIII markers are shown on the left. (B) Restriction map of the 8.9-kb HindIII fragment described above. The shaded box on the right indicates the $0.2-\mathrm{kb}$ HindIII/HindII probe used; the doubleheaded arrows indicate the predicted size of the two hybridising fragments in the Southern blot shown in (A). The dashed line represents the 1.7-kb HindIII/HindII probe used in a subsequent Southern blot experiment. $\mathbf{H}$ and $\mathbf{P}$ indicate cleavage sites for HindIII and Pst I, respectively.

\section{PFGE analysis of NotI-digested genomic DNA}

DNA from strains YSH6000, S2430 and YSH6000T was digested with Not I and analysed by PFGE, thereby confirming that the NotI profile of strain S2430 was altered as previously reported [24, 37], with the $323-\mathrm{kb}$ Not I fragment D absent and in its place a new 224-kb fragment (Fig. 2A). Okada et al. [37] thought that this alteration was caused by Tn5 insertion into Not I fragment $\mathrm{D}$, resulting in the cleavage of the $323-\mathrm{kb}$ fragment into $224-\mathrm{kb}$ and $99-\mathrm{kb}$ fragments. Observation of ethidium bromide-stained PFGs run in the present study could not eliminate completely the possibility of the existence of an additional 99-kb fragment in strain S2430, resulting from the presence of several normal bands in that size range. Strain YSH6000T exhibited a similar alteration of its Not I profile; however, careful examination of the 224-kb fragment in strain S2430 revealed it to be a doublet, which was not present in strain YSH6000T (Fig. 2A). The additional band in strain S2430 was caused by the linearisation of its Tn5bearing $230-\mathrm{kb}$ plasmid resulting from the cleavage of Not I sites contained within Tn5. Southern blots probed with Not I fragment D from strain YSH6000 showed a multi-band profile, consistent with the presence of repeat elements within Not I fragment D. The probe hybridised strongly to the $323-\mathrm{kb}$ band in strain YSH6000 and the 224-kb fragment in both strains S2430 and YSH6000T, but there was no additional 99$\mathrm{kb}$ band derived from Not $\mathrm{I}$ fragment $\mathrm{D}$ in either of the latter two strains (Fig. 2B), proving conclusively that Not I fragment D in both strains S2430 and YSH6000T had undergone a large $99-\mathrm{kb}$ deletion. This finding is consistent with the findings of the subsequent analysis with Not I D-specific probes. The additional strongly hybridising bands seen in lanes 2 and 4 (Fig. 2B) may result from hybridisation with circular pMYSH6000 co-migrating with corresponding chromosomal Not I fragments of strains YSH6000 and YSH6000T, respectively.

\section{Mapping of the deletion on the S. flexneri $2 a$ chromosome}

The Not I PFGE profiles of strains YSH6000, S2430 and YSH6000T showed that the deletion was within 


\section{A}

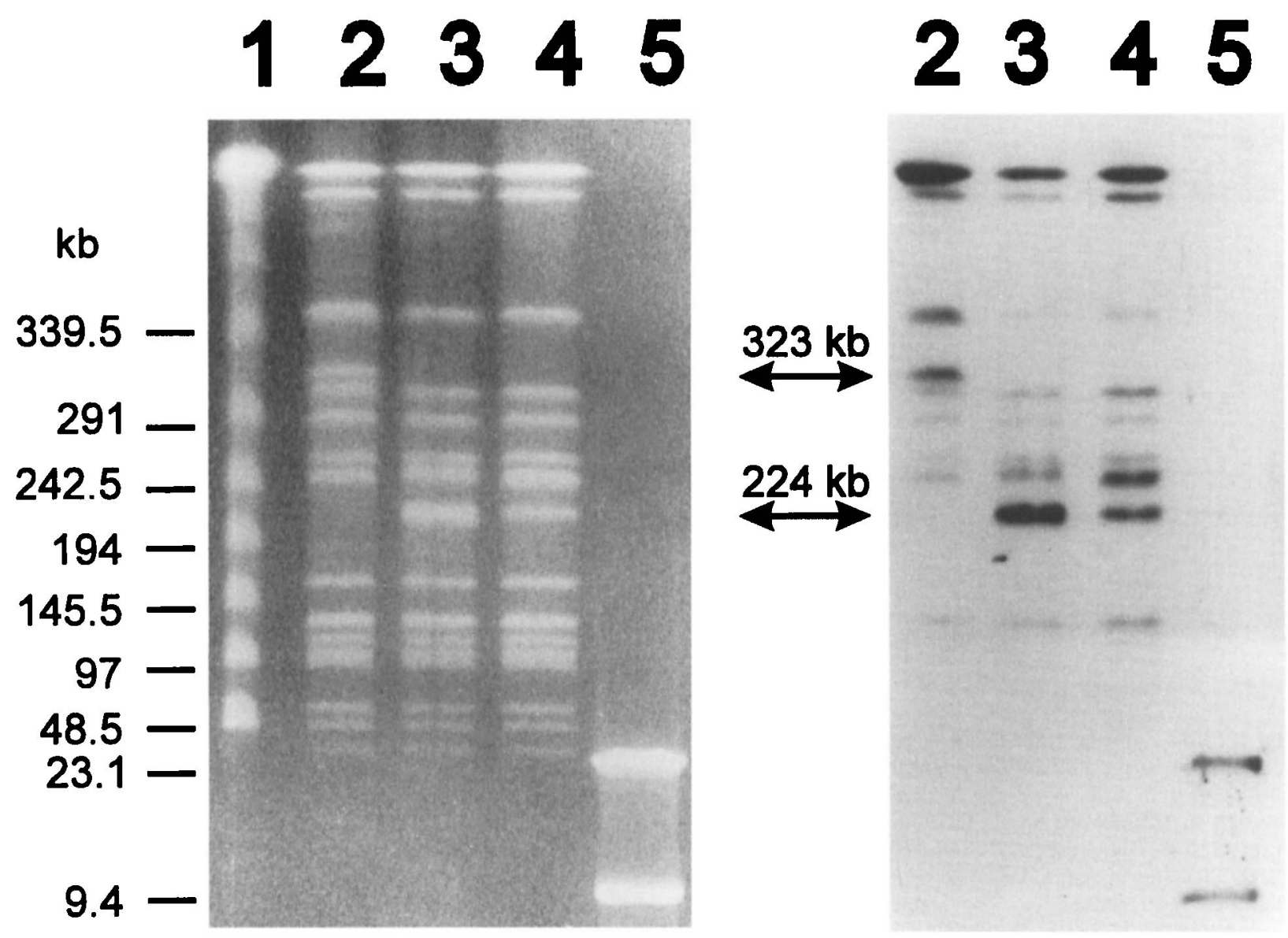

Fig. 2. (A) PFGE profile of NotI-digested DNA of Shigella strains. Lane 1, $\lambda$ concatamers; 2, strain YSH6000 DNA digested with Not $\mathrm{I} ; 3$, strain S2430 DNA digested with Not I; 4, strain YSH6000T DNA digested with NotI; 5, digoxigenin-labelled $\lambda$ HindIII markers. (B) Southern hybridisation analysis of the gel shown in (A) with the Not I fragment D from strain YSH6000 as a probe. Double arrows indicate the positions and sizes of Not I fragment D from strain YSH6000 $(323 \mathrm{~kb})$ and the corresponding truncated fragment in strains S2430 and YSH6000T (224 kb). The positions of standard DNA size markers are shown on the left.

chromosomal Not I fragment D. Okada et al. [37] demonstrated that the E. coli genes ompF, ompA and pyrC hybridised specifically with Not I fragment D of strain YSH6000. To further localise the deletion in strains S2430 and YSH6000T, a strategy involving double-digestion with $N o t \mathrm{I}$ and $S f i \mathrm{I}$, followed by resolution on PFGE and hybridisation with the three NotI D-specific probes identified by Okada et al. [37] was utilised. The results confirmed the presence of ompF, ompA and $\operatorname{pyrC}$ homologues on the 323-kb Not I D fragment of strain YSH6000 and showed that none of the genes was lost following the deletion in strain S2430 or YSH6000T (Fig. 3A-C). In strains S2430 and YSH6000T, all three genes were detected on a 166-kb fragment flanked by Not I or $S f i$ I sites (Fig. 3A-C; lane 2, S2430; lane 3, YSH6000T). Hybridisation of YSH6000 genome with the probes resulted in two bands in each case. With $o m p F$ and $o m p A, 155-\mathrm{kb}$ and 265-kb bands were seen (Fig. 3A and B; lane 1), while pyrC hybridised with $110-\mathrm{kb}$ and $265-\mathrm{kb}$ bands (Fig. $3 \mathrm{C}$; lane 1). This dual-band pattern appeared to be the result of an additional $S f i \mathrm{I}$ site in Not I fragment D of strain YSH6000 that was less susceptible to digestion. Complete digestion would have resulted in only the smaller of the two bands in each case. This proposal is supported by the fact that the sum of the two smaller fragment sizes $(110 \mathrm{~kb}, 155 \mathrm{~kb})$ appeared equal to the $265-\mathrm{kb}$ product of partial digesion that hybridised with each of the three probes. The absence of this additional $S f i$ I site in strains S2430 and YSH6000T indicated that the site lay within the deleted region. Therefore, by mapping this site in strain YSH6000 it was possible to locate more precisely the deletion. As $p y r C$ hybridised with a 110-kb fragment and both ompA and ompF hybridised with a 155 -kb fragment, it was concluded that the deletion occurred between the ompA and $p y r C$ 

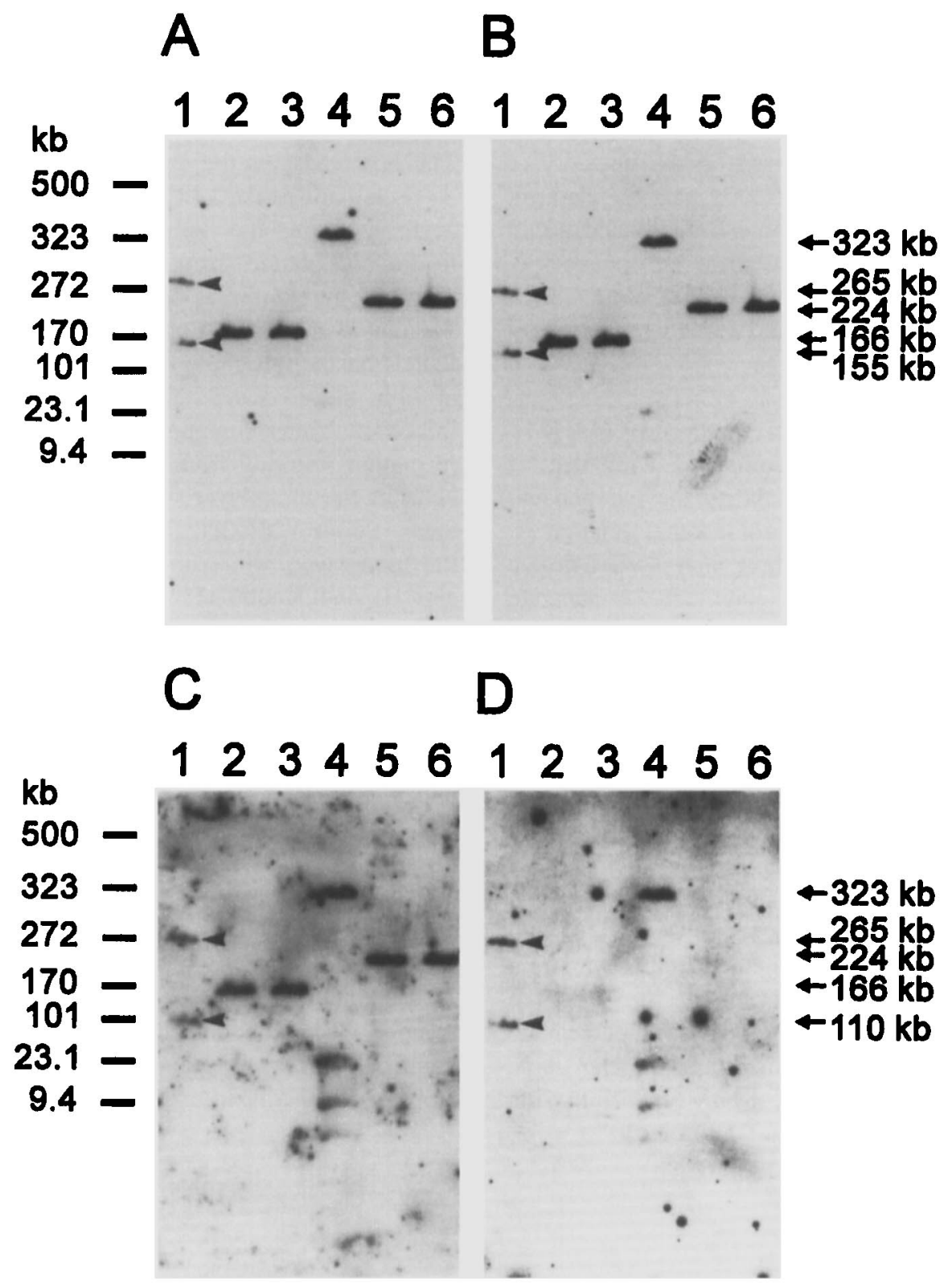

Fig. 3. Southern hybridisation analysis of Not I- and Not $\mathrm{V} / S f i \mathrm{I}$-digested DNA resolved by PFGE. The same membrane was stripped and re-probed with the following probes: $\mathbf{A}, o m p F ; \mathbf{B}, o m p A ; \mathbf{C}, \operatorname{pyr} C ; \mathbf{D}, 0.2-\mathrm{kb} \operatorname{HindIII/HindII~fragment}$ linked to the chloramphenicol and tetracycline resistance determinants. Lane 1, strain YSH6000 DNA digested with Not I/SfiI; 2, strain S2430 DNA digested with Not I/SfiI; 3, strain YSH6000T DNA digested with Not I/Sfi I; 4, strain YSH6000 DNA digested with NotI, plus digoxigenin-labelled $\lambda$ HindIII markers; 5, strain S2430 DNA digested with NotI; 6, strain YSH6000T DNA digested with Not I. Arrows to the right of (A) and (B) indicate the size of the various hybridising fragments in both of these panels. Arrows to the right of (C) and (D) indicate the size of all hybridising fragments seen in (C) and of the three fragments seen in (D). Arrowheads within panels highlight the fainter hybridising bands. The positions of some of the known NotI fragments of strain YSH6000 [37] and of the larger $\lambda$ HindIII fragments, are shown on the left.

homologues of strain YSH6000 (Fig. 6). A further hybridisation experiment probing with the $0.2-\mathrm{kb}$ HindIII/HindlI fragment linked to the resistance determinants confirmed that the deletion resulting in multiple antibiotic susceptibility was the same as that in Not I fragment D (Fig. 3D), and allowed the mapping of this resistance region to the pyrC side of the additional $S f i$ I site.

\section{Virulence phenotype assays}

To clarify the effect of the Tn5 insertion in strain S2430, strains of YSH6000 and YSH6000T, K6000 and K6000T, respectively, carrying $\mathrm{Tn} 5$ in a position identical to that in strain S2430 were constructed by P1 transduction. Hybridisation with a probe derived from DNA flanking the Tn5 in strain S2430 confirmed 
the correct genotype in these transductants. Strains YSH6000, S2430 and YSH6000T were observed during this study to vary in their ability to bind Congo red $\left(\mathrm{Pcr}^{+}\right)$. All three strains were $\mathrm{Pcr}^{+}$; however, it was possible to score the strains based on the intensity of Congo red binding. Strain YSH6000 was the darkest, with strain YSH6000T being intermediate and strain S2430 clearly exhibiting the weakest Pcr phenotype. This result was mirrored by strains K6000 and K6000T, each exhibiting an ability to bind Congo red identical to that of its parent.

Strain S2430 was reported to have reduced CHA [24]. In this study its CHA was compared with that of strains K6000 and K6000T to clarify the independent effects of the $\operatorname{Tn} 5$ and of the chromosomal deletion on $\mathrm{CH}$ phenotype (Fig. 4A). The three strains were grown in trypticase soy broth with kanamycin. A separate comparison between strains YSH6000, YSH6000T and YSH6200, a virulence-plasmid-free derivative of strain YSH6000, grown in antibiotic-free broth was also performed (Fig. 4B). Strain YSH6200 did not induce any haemolysis. Within the range of $\left(1 \times 10^{9}\right)$ $\left(5 \times 10^{9}\right) \mathrm{cfu} / \mathrm{ml}$, both strains S2430 and K6000T exhibited significantly lower levels of haemolysis than strain K6000. Strains S2430 and K6000T displayed similar values of $\mathrm{CH}$,throughout this range. At $3 \times 10^{9} \mathrm{cfu} / \mathrm{ml}$ the CHA of strains $\mathrm{S} 2430$ and $\mathrm{K} 6000 \mathrm{~T}$, expressed as a percentage of that of strain K6000, was $46 \%$ and $47 \%$ respectively. Similarly, the CHA of strain YSH6000T, expressed as a percentage of that of strain YSH6000, measured at the same bacterial concentration was $48 \%$, supporting the conclusion that the attenuation in this phenotype was wholly attributable to the deletions in strains S2430 and YSH6000T.

The Fpa measures the ability of the bacteria to invade an initial cell in the LLC-MK2 monolayer, resulting in a focus, and the subsequent intercellular spread leading to plaque formation. Strain S2430 has been reported to exhibit a delayed $\mathrm{Fpa}^{+}$phenotype [24]. Results of a typical Fpa assay are shown in Fig. 5. Panels on the left show the extent of plaque formation at $24 \mathrm{~h}$; those on the right show plaques at $40 \mathrm{~h}$ postinfection. Under low power light microscopy plaque formation resulting from the destruction of contiguous cells in the monolayer was apparent as dark granular areas. Strain YSH6200 (Fig. 5K and L) did not infect the monolayer, while both strains YSH6000 (Fig. 5G and $\mathrm{H}$ ) and $\mathrm{K} 6000$ (Fig. 5A and B) showed normal progression with significant plaque formation after 24 h. Strains YSH6000T (Fig. 5I and J) and K6000T (Fig. 5E and F) exhibited an Fpa phenotype indistinguishable from that of strain YSH6000. However, strain S2430 (Fig. 5C and D) clearly exhibited a delay in its Fpa phenotype, requiring $>48 \mathrm{~h}$ to form plaques similar to those produced at $24 \mathrm{~h}$ by the wildtype strain.

\section{Discussion}

A large 99-kb spontaneous chromosomal deletion was identified in two independent strains of $S$. flexneri $2 \mathrm{a}$. No data are available on the frequency of this deletion
A

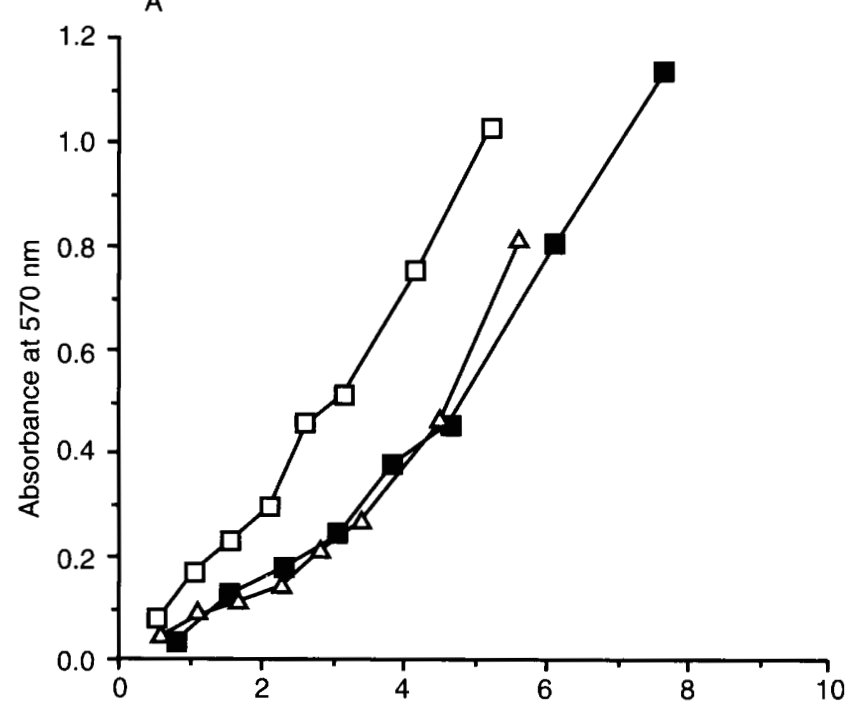

B

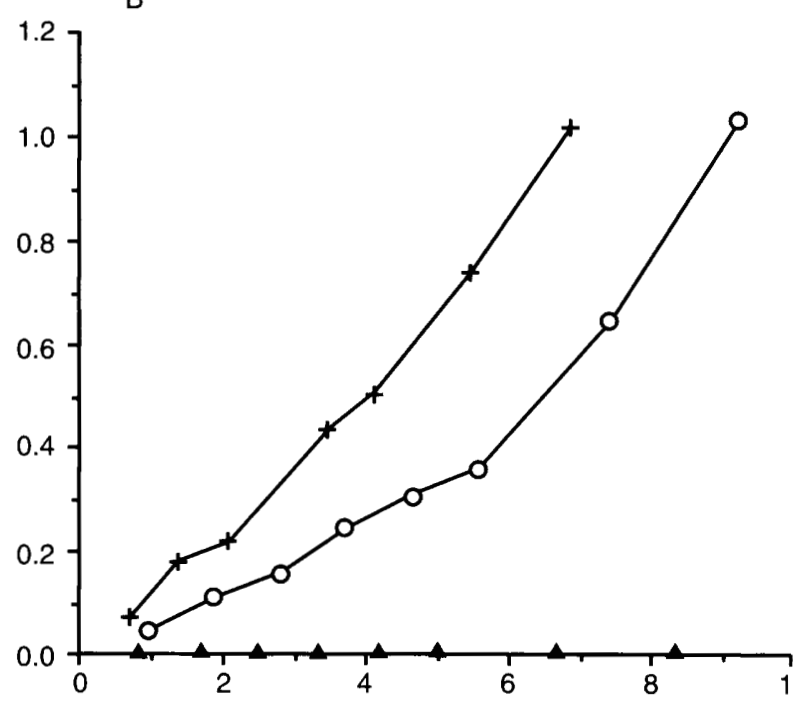

Concentration of bacteria $\left(\times 10^{9} \mathrm{ml}^{-1}\right)$

Fig. 4. Contact haemolytic activity of Shigella strains: A, K6000 ( $\square$ ), K6000T ( $\square)$ and S2430 ( $\triangle$ ) were grown in trypticase soy broth containing kanamycin $50 \mathrm{mg} / \mathrm{L}$; B, YSH6000(+), YSH6000T $(\mathrm{O})$ and YSH6200 $(\mathbf{\Delta})$ were grown in trypticase soy broth alone. All strains were harvested and concentrated after incubation for $3 \mathrm{~h}$ at $37^{\circ} \mathrm{C}$. Contact haemolytic activity was measured by recording the $\mathrm{A}_{570 \mathrm{~nm}}$ of the supernate after incubation for $1 \mathrm{~h}$ with sheep erythrocytes. Absorbance measurements and bacterial counts shown represent the means from four replicates. The data shown reflect the results of duplicate experiments. 


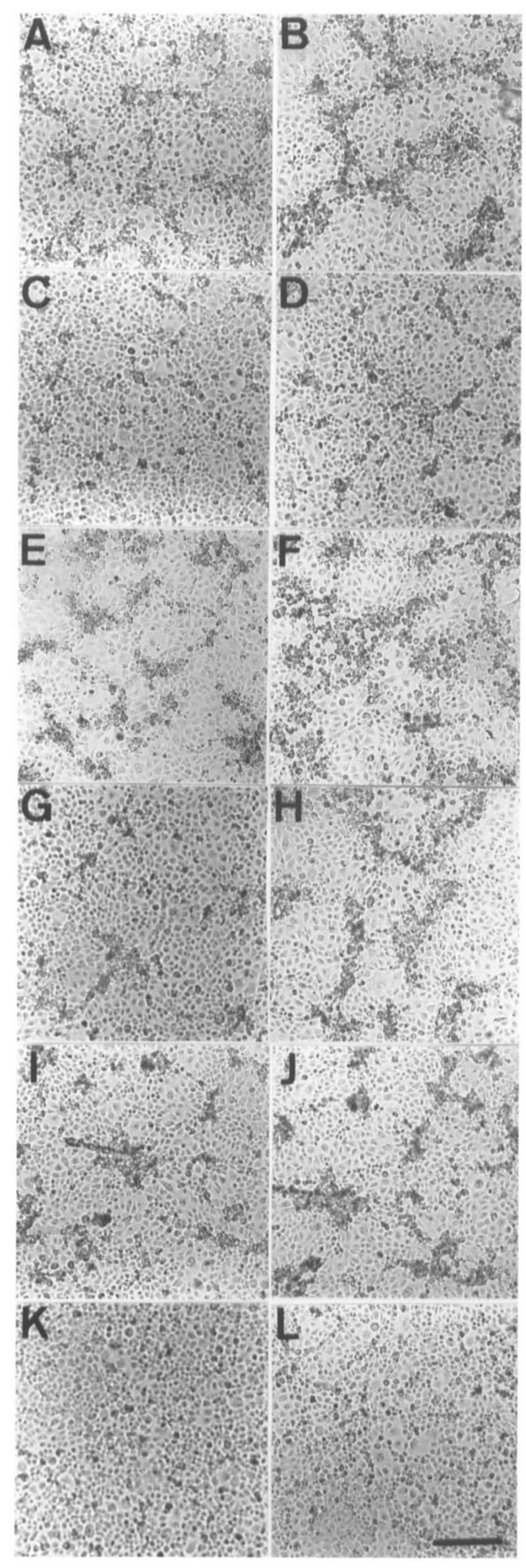

event in $S$. flexneri, although comparable genetic alterations in $E$. coli and Yersinia pestis occur at frequencies of $10^{-5}-10^{-3}$ [38]. The deletion was mapped to a region of Not I fragment D, bounded by the $S$. flexneri homologues of ompA and pyrC. Okada et al. [37] had shown previously that the serS and the $p t s G$ genes hybridised respectively with Not I fragments $\mathrm{K}$ and $\mathrm{O}$, which flank fragment $\mathrm{D}$. Given this, and the similarity in genetic organisation between $E$. coli $\mathrm{K}-12$ and $S$. flexneri 2a [37], a direct comparison between the $E$. coli linkage map and of the corresponding region of the $S$. flexneri 2 a chromosome was attempted (Fig. 6). The spacing between ompF and pyrC in $E$. coli is $120 \mathrm{~kb}[39,40]$, while in $S$. flexneri 2a strain YSH6000 the postulated approximate spacing is $220 \mathrm{~kb}$ but is 'restored' to $120 \mathrm{~kb}$ in the two spontaneous deletants. This coincidence of sizes suggests that strain YSH6000 evolved after the insertion of a large element into this region, whilst strain YSH6000T may be representative of an ancestral form of the wild-type strain YSH6000 (Fig. 6).

There have been several reports regarding the insertion of large elements, frequently plasmids, into the genome of bacteria [41]. Some of these plasmids have been shown to exist either as chromosomal or extra-chromosomal elements $[42,43]$. Strain YSH6000 itself harbours a $230-\mathrm{kb}$ virulence plasmid that is able to insert spontaneously into the metB gene on the chromosome resulting in loss of virulence. Virulence is restored following spontaneous excision of the plasmid [44]. Further presumptive evidence supporting the insertion hypothesis is the presence of two serine tRNA genes within the corresponding region of the $E$. coli genome [39,45]. tRNA genes have been shown to serve frequently as targets for plasmid or phage insertion. Such insertions occur through homologous recombination between specific chromosomal and plasmid sequences, often resulting in the reconstitution of the target gene $[41,46]$. Recently, Blum et al. [47] described the spontaneous deletion of 'islands of pathogenicity' in $E$. coli. The deleted regions of $70 \mathrm{~kb}$ and $190 \mathrm{~kb}$ that encode haemolysins and Prelated fimbrial genes have been mapped precisely to tRNA genes. The two tRNA species are produced by the parent strain but neither is synthesised by the spontaneous double deletants. Sequence data across the point of excision confirmed a disruption of the tRNA genes [47], while Leong et al. [48], by $ø 80$ mediated site-specific inversion, demonstrated the

Fig. 5. Low power light microscopy showing plaque formation in LLC-MK2 cell monolayers infected with different strains of $S$. flexneri 2a. (A) and (B), strain $\mathrm{K} 6000 ;(\mathbf{C})$ and (D), strain S2430; (E) and (F), strain K6000T; (G) and (H), strain YSH6000; (I) and (J), strain YSH6000T; $(\mathbf{K})$ and (L), strain YSH6200. Panels on the left show typical plaque formation at $24 \mathrm{~h}$; panels on the right reflect plaque formation at $40 \mathrm{~h}$. The bar in panel (L) represents $400 \mu \mathrm{m}$. 

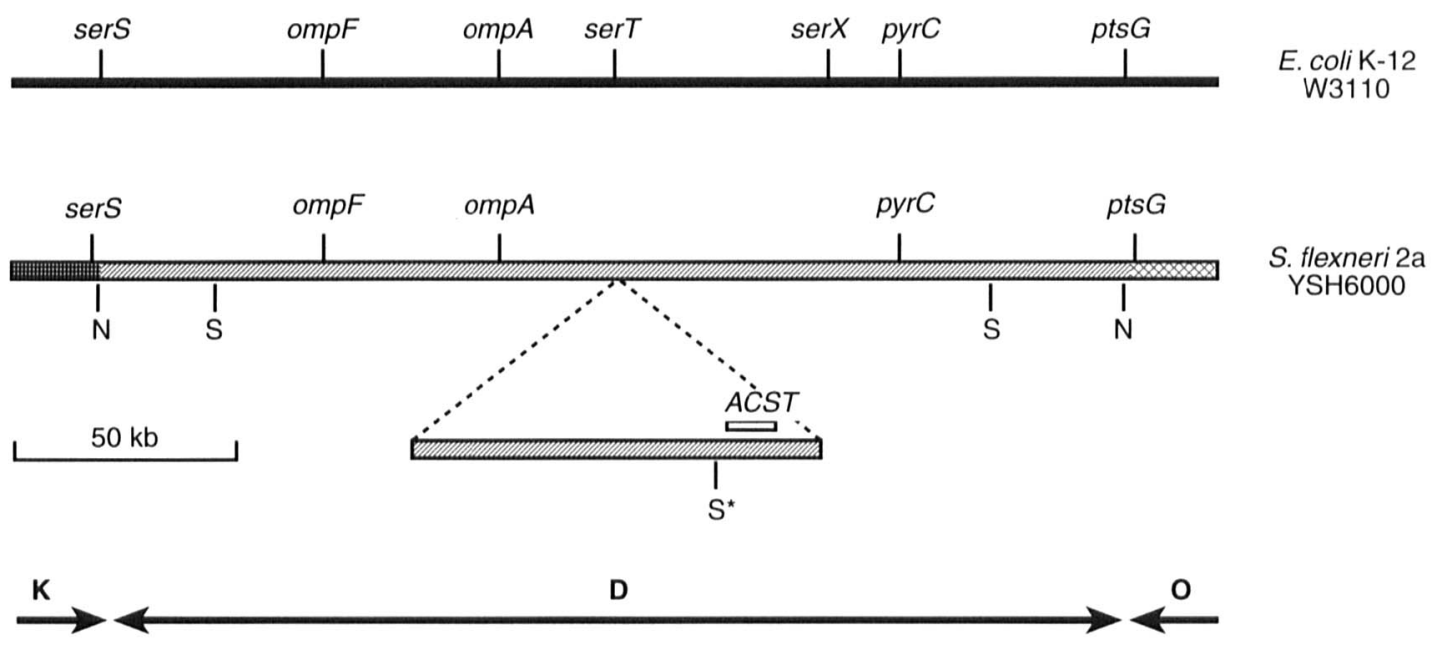

Fig. 6. Comparison of the genetic map of E. coli K-12 W3110 [39,40] and of the hypothetical map of S. flexneri 2a YSH6000 between serS and ptsG. In S. flexneri 2a YSH6000 serS and ptsG are known to lie within NotI fragments K and $\mathrm{O}$ respectively, while ompF, ompA and $p y r C$ lie on Not I fragment D [37]. The precise placement of these genes on the YSH6000 map remains speculative. To clarify the postulated gene alignment between these bacterial species, the 99-kb span of DNA deleted in strains S2430 and YSH6000T is shown as a lower hatched bar. The exact location of the deletion and of the resistance region (ACST) contained within remains to be determined. Sfi I (S) sites shown have not been mapped and their placement as shown is in order to allow a schematic representation of the model. $\mathbf{N}$, indicates Not I sites while the asterisk highlights the $S f i$ I site that is partially resistant to digestion. The arrows at the bottom of the figure indicate the various Not I fragments.

occurrence of single base-pair substitutions, deletions and insertions during these homologous recombination events. Furthermore, Durand et al. [49] have reported that a mutation of $v a c C$, a gene encoding tRNAguanine transglycosylase, results in an altered virulence phenotype in $S$. flexneri, supporting the possibility that the mutation of a tRNA gene may affect virulence in Shigella spp.

The insertion of $\operatorname{Tn} 5$ in the virulence plasmid of strain S2430 was shown to have no effect on the virulence phenotype of that strain. The two P1 transductants, strains K6000 and K6000T, each had a virulence phenotype identical to that of its parent. On the other hand, this study demonstrated that the 99-kb deletion occurring in both strains S2430 and YSH6000T resulted in an attenuation of CHA and of Congo red binding. The correlation between the ability to bind Congo red and virulence in $S$. flexneri has been well established [50]. Others have shown that a reduction in CHA is associated with decreased primary invasion and impaired escape from the endocytic vacuole $[3,35]$. However, despite the reduced $\mathrm{CHA}$ of strain YSH6000T, unlike strain S2430 it did not exhibit a delayed Fpa phenotype. This finding suggests that the reduction in CHA of strain S2430 is unrelated to its activity in the Fpa assay. Unlike previous studies in which attenuated strains exhibited a reduction in $\mathrm{CHA}$ of $>90 \%[3,35]$, both strains S2430 and YSH6000T still exhibited c. $50 \%$ of wild-type CHA. This level of residual $\mathrm{CHA}$ was presumably sufficient to promote normal plaque-forming ability. A similar phenomenon was described by High et al. [3] in which a complemented $S$. flexneri mutant exhibiting only a partial restoration of its haemolytic phenotype was restored to full invasive capacity in the HeLa cell assay. Nevertheless, the strong link between CHA and virulence in Shigella spp., as established by others $[3,35]$, supports our conclusion that the 99-kb chromosomal deletion results in the loss of a virulence-associated attribute.

The possibility that a further unrelated mutation in strain S2430 was responsible for the delayed Fpa phenotype is highly improbable, given that three independent genetic events would have had to coincide. Furthermore, as the SalI profiles of the virulence plasmid from strains S2430 and YSH6000 differed only with respect to SalI fragment $\mathrm{K}$, an unrecognised deletion in the plasmid is unlikely. A more likely hypothesis is that this phenotypic difference is due to a small difference in the extent of the chromosomal deletion between these strains or the possibility that the deletion in strain YSH6000T is precise, whilst that in strain $\mathrm{S} 2430$ is imprecise, resulting in a mutated target gene. Confirmation of this hypothesis must await the precise identification of the endpoints of these deletion events.

Small deletions in virulence loci have been shown in several bacterial genera $[38,51]$. However, besides $E$. coli [47] and now S. flexneri, the only other bacterial species known to us that has been shown to exhibit a large spontaneous chromosomal deletion resulting in an attenuation of virulence phenotype is $Y$. pestis [52,53]. Fetherston et al. [52] and Lucier and Brubaker [53] have measured the deletion in Y. pestis at $102 \mathrm{~kb}$. The $Y$. pestis deletant exhibited an alteration 
of the Pcr phenotype, but unlike the S. flexneri strains, in which there was only a reduction of dye binding, the $Y$. pestis deletant displayed a $\mathrm{Pcr}^{-}$phenotype [52]. Besides Congo red binding, the deleted $Y$. pestis DNA encodes iron-regulated proteins, some of which probably form an iron transport system required for growth at $37^{\circ} \mathrm{C}$ in iron-deficient media [54]. Lawlor and Payne [55] have described deletions in the chromosome of $S$. flexneri involving the aerobactin genes, although these deletions appear to be of variable size and are not well defined. The 99-kb deletion in $S$. flexneri $2 \mathrm{a}$ is unlikely to involve these genes as strain S2430 grew well in iron-depleted medium (data not shown) and the genes probably map to a different region of the chromosome [56].

Antibiotic multi-resistance in bacteria, especially Shigella spp., is frequently associated with plasmids, but chromosomally encoded resistance has also been described. Chromosomal antibiotic-multi resistance loci have been identified and cloned in $E$. coli [57, 58] and Pseudomonas aeruginosa [59]. Sequence and functional analysis of the locus in $E$. coli showed it to consist of an operon of three genes, $\operatorname{marR} A B$, that exert a regulatory effect on several distant genes including $o m p F$ [57]. Resistance probably arises from an alteration in transport of a broad range of drugs across the bacterial membrane.

A mar locus, highly homologous to that in E. coli, has been identified in other members of the family Enterobacteriaceae including Shigella spp. [60]. However, the deletion in strain YSH6000 is unlikely to involve the equivalent locus for the following reasons. Firstly, strain YSH6000 exhibits high resistance to ampicillin, streptomycin, tetracycline and chloramphenicol whilst remaining susceptible to low concentrations of nalidixic acid, unlike the resistance pattern mediated by the E. coli mar locus. Secondly, the ability to clone the chloramphenicol and tetracycline resistance determinants on a fragment separate from the streptomycin resistance determinant strongly argues against an $E$. coli-type locus in which a single operon is responsible for all resistances. Indeed, recent work in this laboratory suggests the presence of $\beta$ lactamase and chloramphenicol acetyl transferase genes within the deleted region. Thirdly, the deletion in strain YSH6000 corresponds to position $22 \mathrm{~min}$ on the $E$. coli chromosome, whilst the $E$. coli mar locus has been mapped to $34 \mathrm{~min}$ [58]. Finally, the likelihood of ISI elements being associated with the resistance region identified in this study points to a similarity with resistance determinants associated with resistance plasmids [61], such as the IncFII plasmids, $\mathrm{R} 1$ and R100. In these plasmids the resistance determinants are flanked by two directly repeated copies of IS $I$ and arise from a series of intercalated transposable elements carrying multiple individual resistance genes [62]. Further ongoing characterisation of this $S$. flexneri antibiotic-multi resistance region should clarify the issue. A similar phenomenon involving the loss of an antibiotic-multi resistance region has been reported in Staphylococcus aureus, in which Inglis et al. [63] described the PFGE characterisation of methicillin-resistant and methicillinsensitive strains. They found that the sensitive strains exhibited profiles similar to laboratory variants that have lost c. $40-70 \mathrm{~kb}$ of DNA carrying multiple resistance determinants clustered around the methicillin resistance gene [63].

Numerous epidemiological studies have consistently highlighted the prevalence and variety of antibioticmulti resistance plasmids in Shigella spp. [21-23]. The four-drug resistance pattern of strain YSH6000 is common amongst clinical isolates [21]. The possibility that strain YSH6000 arose after the acquisition of an R-plasmid that subsequently integrated and stabilised within the genome, possibly as a result of incompatibility with another IncFII plasmid, the 230-kb virulence factor [64], remains an intriguing possibility.

This work was supported by a grant from the National Health and Medical Research Council, Canberra, Australia. K.R. was the recipient of a Macfarlane Burnet Biomedical Research Scholarship. The authors gratefully acknowledge the assistance of F. Luo in performing some experiments preliminary to this study.

\section{References}

1. Sansonetti PJ. Molecular and cellular biology of Shigella flexneri invasiveness: from cell assay systems to shigellosis. Curr Top Microbiol Immunol 1992; 180: 1-19.

2. Sasakawa C, Buysse JM, Watanabe H. The large virulence plasmid of Shigella. Curr Top Microbiol Immunol 1992; 180: $21-44$.

3. High N, Mounier J, Prévost MC, Sansonetti PJ. IpaB of Shigella flexneri causes entry into epithelial cells and escape from the phagocytic vacuole. EMBO J 1992; 11: 1991-1999.

4. Sasakawa $\mathrm{C}$, Adler B, Tobe $\mathrm{T}$ et al. Functional organization and nucleotide sequence of virulence Region-2 on the large virulence plasmid in Shigella flexneri 2a. Mol Microbiol 1989; 3: $1191-1201$.

5. Clerc P, Sansonetti PJ. Entry of Shigella flexneri into HeLa cells: evidence for directed phagocytosis involving actin polymerization and myosin accumulation. Infect Immun 1987; 55: $2681-2688$

6. Allaoui A, Mounier J, Prévost M-C, Sansonetti PJ, Parsot C. icsB: a Shigella flexneri virulence gene necessary for the lysis of protrusions during intercellular spread. Mol Microbiol 1992; 6: $1605-1616$.

7. Suzuki T, Murai T, Fukuda I, Tobe T, Yoshikawa M, Sasakawa C. Identification and characterization of a chromosomal virulence gene, vacJ, required for intercellular spreading of Shigella flexneri. Mol Microbiol 1994; 11: 31-41.

8. Andrews GP, Hromockyj AE, Coker C, Maurelli AT. Two novel virulence loci, mxiA and $m x i B$, in Shigella flexneri 2a facilitate excretion of invasion plasmid antigens. Infect Immun 1991; 59: 1997-2005.

9. Sasakawa C, Komatsu K, Tobe T, Suzuki T, Yoshikawa M. Eight genes in region 5 that form an operon are essential for invasion of epithelial cells by Shigella flexneri 2a. J Bacteriol 1993; 175: 2334-2346.

10. Venkatesan MM, Buysse JM, Oaks EV. Surface presentation of Shigella flexneri invasion plasmid antigens requires the products of the spa locus. J Bacteriol 1992; 174: 1990-2001.

11. Bernardini ML, Mounier J, d'Hauteville $H$, Coquis-Rondon $M$, Sansonetti PJ. Identification of icsA, a plasmid locus of Shigella flexneri that governs bacterial intra- and intercellular spread through interaction with F-actin. Proc Natl Acad Sci 
USA 1989; 86: 3867-3871.

12. Nakata N, Sasakawa $\mathrm{C}$, Okada $\mathrm{N}$ et al. Identification and characterization of $v i r K$, a virulence-associated large plasmid gene essential for intercellular spreading of Shigella flexneri. Mol Microbiol 1992; 6: 2387-2395.

13. Adler B, Sasakawa C, Tobe T, Makino S, Komatsu K Yoshikawa M. A dual transcriptional activation system for the $230 \mathrm{~kb}$ plasmid genes coding for virulence-associated antigens of Shigella flexneri. Mol Microbiol 1989; 3: 627-635.

14. Sakai T, Sasakawa C, Yoshikawa M. Expression of four virulence antigens of Shigella flexneri is positively regulated at the transcriptional level by the 30 kiloDalton virF protein. Mol Microbiol 1988; 2: 589-597.

15. Hromockyj AE, Tucker SC, Maurelli AT. Temperature regulation of Shigella virulence: identification of the repressor gene $\operatorname{vir} R$, an analogue of $h n s$, and partial complementation by tyrosyl transfer RNA (tRNA 1 Tyr $)$. Mol Microbiol 1992; 6: 2113-2124.

16. Bernardini ML, Fontaine A, Sansonetti PJ. The two-component regulatory system OmpR-EnvZ controls the virulence of Shigella flexneri. J Bacteriol 1990; 172: 6274-6281.

17. Lindberg AA, Kärnell A, Weintraub A. The lipopolysaccharide of Shigella bacteria as a virulence factor. Rev Infect Dis 1991; 13 Suppl 4: S279-S284.

18. Nassif X, Mazert M-C, Mounier J, Sansonetti PJ. Evaluation with an iuc:: $\operatorname{Tn} 10$ mutant of the role of aerobactin production in the virulence of Shigella flexneri. Infect Immun 1987; 55: 1963-1969.

19. Franzon VL, Arondel J, Sansonetti PJ. Contribution of superoxide dismutase and catalase activities to Shigella flexneri pathogenesis. Infect Immun 1990; 58: 529-535.

20. Tobe T, Sasakawa C, Okada N, Honma Y, Yoshikawa M. vacB, a novel chromosomal gene required for expression of virulence genes on the large plasmid of Shigella flexneri. $J$ Bacteriol 1992; 174: 6359-6367.

21. Adeleye IA. Conjugal transferability of multiple antibiotic resistance in the three genera of Enterobacteriaceae in Nigeria. $J$ Diarrhoeal Dis Res 1992; 10: 93-96.

22. Ling JM, Shaw PC, Kam KM, Cheng AF, French GL. Molecular studies of plasmids of multiply-resistant Shigella spp. in Hong Kong. Epidemiol Infect 1993; 110: 437-446.

23. Gebre-Yohannes A, Drasar BS. Plasmid profiles of antibioticresistant Shigella dysenteriae types 2, 3, 4, 6 and 7 isolated in Ethiopia during 1976-85. Epidemiol Infect 1990; 105: 65-72.

24. Okada N, Sasakawa C, Tobe $\mathrm{T}$ et al. Virulence-associated chromosomal loci of Shigella flexneri identified by random Tn5 insertion mutagenesis. Mol Microbiol 1991; 5: 187-195.

25. Sasakawa C, Kamata K, Sakai T, Murayama SY, Makino S, Yoshikawa M. Molecular alteration of the 140-megadalton plasmid associated with loss of virulence and Congo red binding activity in Shigella flexneri. Infect Immun 1986; 51: $470-475$.

26. Ausubel FM, Brent R, Kingston RE et al. (eds). Current protocols in molecular biology. New York, Greene Publishing Associates and Wiley-Interscience. 1991.

27. Morelle G. A plasmid extraction procedure on a miniprep scale. Focus 1989; 11: 7-8.

28. Rajakumar K, Jost BH, Sasakawa C, Okada N, Yoshikawa M, Adler B. Nucleotide sequence of the rhamnose biosynthetic operon of Shigella flexneri $2 \mathrm{a}$ and role of lipopolysaccharide in virulence. J Bacteriol 1994; 176: 2362-2373.

29. Makino S, Sasakawa C, Yoshikawa M. Genetic relatedness of the basic replicon of the virulence plasmid in shigellae and enteroinvasive Escherichia coli. Microb Pathog 1988; 5: 267274.

30. Sanger F, Nicklen S, Coulson AR. DNA sequencing with chain-terminating inhibitors. Proc Natl Acad Sci USA 1977; 74: $5463-5467$

31. Smith CL, Cantor CR. Purification, specific fragmentation, and separation of large DNA molecules. Methods Enzymol 1987; 155: 449-467.

32. Freudl R. Insertion of peptides into cell-surface-exposed areas of the Escherichia coli OmpA protein does not interfere with export and membrane assembly. Gene 1989; 82: 229-236.

33. Inokuchi $\mathrm{K}$, Mutoh $\mathrm{N}$, Matsuyama $\mathrm{S}$, Mizushima S. Primary structure of the ompF gene that codes for a major outer membrane protein of Escherichia coli K-12. Nucleic Acids Res 1982; 10: 6957-6968.

34. Wilson HR, Chan PT, Turnbough CL. Nucleotide sequence and expression of the pyrC gene of Escherichia coli K-12.
J Bacteriol 1987; 169: 3051-3058

35. Sansonetti PJ, Ryter A, Clerc P, Maurelli AT, Mounier J. Multiplication of Shigella flexneri within HeLa cells: lysis of the phagocytic vacuole and plasmid-mediated contact hemolysis. Infect Immun 1986; 51: 461-469.

36. Sasakawa C, Kamata K, Sakai $T$ et al. Virulence-associated genetic regions comprising 31 kilobases of the 230-kilobase plasmid in Shigella flexneri 2a. J Bacteriol 1988; 170: 2480 2484 .

37. Okada N, Sasakawa C, Tobe T, Talukder KA, Komatsu K, Yoshikawa M. Construction of a physical map of the chromosome of Shigella flexneri $2 \mathrm{a}$ and the direct assignment of nine virulence-associated loci identified by Tn5 insertions. Mol Microbiol 1991; 5: 2171-2180.

38. Ott M. Dynamics of the bacterial genome: deletions and integrations as mechanisms of bacterial virulence modulation Int J Med Microbiol Virol Parasitol Infect Dis 1993; 278: 457468.

39. Bachmann BJ. Linkage map of Escherichia coli K-12, edition 8. Microbiol Rev 1990; 54: 130-197.

40. Médigue C, Hénaut A, Danchin A. Escherichia coli molecular genetic map (1000 kbp): update 1. Mol Microbiol 1990; 4: 1443-1454.

41. Campbell AM. Chromosomal insertion sites for phages and plasmids. J Bacteriol 1992; 174: 7495-7499.

42. Bar-Nir D, Cohen A, Goedeke ME. tDNA ${ }^{\text {ser }}$ sequences are involved in the excision of Streptomyces griseus plasmid pSG1. Gene 1992; 122: 71-76.

43. $\mathrm{Ka} \mathrm{JO}$, Tiedje JM. Integration and excision of a 2,4dichlorophenoxyacetic acid-degradative plasmid in Alcaligenes paradoxus and evidence of its natural intergeneric transfer J Bacteriol 1994; 176: 5284-5289.

44. Zagaglia C, Casalino M, Colonna B, Conti C, Calconi A, Nicoletti M. Virulence plasmids of enteroinvasive Escherichia coli and Shigella flexneri integrate into a specific site on the host chromosome: integration greatly reduces expression of plasmid-carried virulence genes. Infect Immun 1991; 59: 792799.

45. Komine $Y$, Adachi $T$, Inokuchi $H$, Ozeki $H$. Genomic organization and physical mapping of the transfer RNA genes in Escherichia coli K12. J Mol Biol 1990; 212: 579-598.

46. Reiter W-D, Palm P, Yeats S. Transfer RNA genes frequently serve as integration sites for prokaryotic genetic elements. Nucleic Acids Res 1989; 17: 1907-1914.

47. Blum G, Ott M, Lischewski A et al. Excision of large DNA regions termed pathogenicity islands from tRNA-specific loci in the chromosome of an Escherichia coli wild-type pathogen. Infect Immun 1994; 62: 606-614.

48. Leong JM, Nunes-Duby SE, Landy A. Generation of single base-pair deletions, insertions, and substitutions by a sitespecific recombination system. Proc Natl Acad Sci USA 1985; 82: 6990-6994.

49. Durand JM, Okada $\mathrm{N}$, Tobe $\mathrm{T}$ et al. vacC, a virulenceassociated chromosomal locus of Shigella flexneri, is homologous to $\mathrm{tgt}$, a gene encoding tRNA-guanine transglycosylase (Tgt) of Escherichia coli K-12. J Bacteriol 1994; 176: 46274634 .

50. Maurelli AT, Blackmon B, Curtiss R. Loss of pigmentation in Shigella flexneri $2 \mathrm{a}$ is correlated with loss of virulence and virulence-associated plasmid. Infect Immun 1984; 43: 397-401.

51. Monack DM, Arico B, Rappuoli R, Falkow S. Phase variants of Bordetella bronchiseptica arise by spontaneous deletions in the vir locus. Mol Microbiol 1989; 3: 1719-1728.

52. Fetherston JD, Schuetze P, Perry RD. Loss of the pigmentation phenotype in Yersinia pestis is due to the spontaneous deletion of $102 \mathrm{~kb}$ of chromosomal DNA which is flanked by a repetitive element. Mol Microbiol 1992; 6: 2693-2704.

53. Lucier TS, Brubaker RR. Determination of genome size, macrorestriction pattern polymorphism, and nonpigmentationspecific deletion in Yersinia pestis by pulsed-field gel electrophoresis. $J$ Bacteriol 1992; 174: 2078-2086.

54. Fetherston JD, Perry RD. The pigmentation locus of Yersinia pestis KIM6+ is flanked by an insertion sequence and includes the structural genes for pesticin sensitivity and HMWP2. Mol Microbiol 1994; 13: 697-708.

55. Lawlor KM, Payne SM. Aerobactin genes in Shigella spp. $J$ Bacteriol 1984; 160: 266-272.

56. Griffiths E, Stevenson P, Hale TL, Formal SB. Synthesis of aerobactin and a 76,000-dalton iron-regulated outer membrane protein by Escherichia coli K-12-Shigella flexneri hybrids and 
by enteroinvasive Escherichia coli. Infect Immun 1985; 49: 6771

57. Cohen SP, Hächler H, Levy SB. Genetic and functional analysis of the multiple antibiotic resistance (mar) locus in Escherichia coli. J Bacteriol 1993; 175: 1484-1492.

58. Hächler $\mathrm{H}$, Cohen SP, Levy SB. marA, a regulated locus which controls expression of chromosomal multiple antibiotic resistance in Escherichia coli. J Bacteriol 1991; 173: 5532-5538.

59. Poole K, Krebes K, McNally C, Neshat S. Multiple antibiotic resistance in Pseudomonas aeruginosa: evidence for involvement of an efflux operon. J Bacteriol 1993; 175: 7363-7372.

60. Cohen SP, Yan W, Levy SB. A multidrug resistance regulatory chromosomal locus is widespread among enteric bacteria. $J$ Infect Dis 1993; 168: 484-488.
61. Ramirez-Santos J, Alvarez G, Cisneros E, Gomez-Eichelmann MC. Distribution of insertion sequence IS 1 in multipleantibiotic resistant clinical Enterobacteriaceae strains. FEMS Microbiol Lett 1992; 93: 189-194.

62. Womble DD, Rownd RH. Genetic and physical map of plasmid NR1: comparison with other IncFII antibiotic resistance plasmids. Microbiol Rev 1988; 52: 433-451.

63. Inglis B, El-Adhami W, Stewart PR. Methicillin-sensitive and resistant homologues of Staphylococcus aureus occur together among clinical isolates. J Infect Dis 1993; 167: 323-328.

64. Silva RM, Saadi S, Maas WK. A basic replicon of virulenceassociated plasmids of Shigella spp. and enteroinvasive Escherichia coli is homologous with a basic replicon in plasmids of IncF groups. Infect Immun 1988; 56: 836-842. 